\title{
PENGARUH PERBEDAAN KONSENTRASI GLISEROL DALAM SUSU SKIM KUNING TELUR UNTUK PROSES PENYIMPANAN SPERMA BEKU TERHADAP MOTILITAS DAN VIABILITAS SPERMATOZOA IKAN PATIN (Pangasius pangasius)
}

\section{EFFECT OF DIFFERENT GLYCEROL CONCENTRATION IN SKIM MILK AND EGG YOLK DILUTER FOR STORAGE PROCESS OF FROZEN SEMEN ON SPERM MOTILITY AND VIABILITY OF CATFISH (Pangasius pangasius)}

\author{
Bagus Rizki Novianto, Sudarno dan Endang Dewi Masithah \\ Fakultas Perikanan dan Kelautan Universitas Airlangga \\ Kampus C Mulyorejo - Surabaya, 60115 Telp. 031-5911451
}

\begin{abstract}
Needs of catfish seed always increase every years, especially for farming activities. Fulfillment demand of seed in large quntities and continuing are the main obstacle in the production process of catfish. This can be overcome by the process of cryopreservation. This process requires diluents and cryoprotectants to maintain the fertility of spermatozoa. Skim milk and egg yolks diluents has been used on fish because it was applied to carp and showing a good result of sperm motility and fertilization rate. Glycerol as cryoprotectant was reported effective to be used for European Catfish than the other kind cryoprotectant.

This study aimed to determine the effect of different concentrations of glycerol in the diluent skim milk and egg yolk on the motility and viability of catfish (Pangasius pangasius) spermatozoa after freezing. This research method is the experiment with completely randomized design (CRD) as the experimental design. The treatment used is different glycerol concentrations, P1 (11\%), P2 (13\%), P3 $(15 \%)$, and $\mathrm{P} 4(17 \%)$ and each of the treatment was repeated 5 times. The main parameters measured were motility $(\%)$ and viability $(\%)$ of spermatozoa. Supporting parameters include odor, color, $\mathrm{pH}$, viscosity, sperm concentration and catfish (Pangasius pangasius). Analysis of the data using Analysis Of Variance (ANOVA) and to determine the best treatment performed Duncan's Multiple Range Test with $95 \%$ confidance interval.

The results showed that the effect of the concentration of glycerol in the diluent skim milk and egg yolk was not significantly ( $>>0.05)$ on the motility and viability of catfish (Pangasius pangasius) spermatozoa after freezing. Further testing needs to be done on the level of fertility of frozen sperm, as well as the growth rate of seeds produced from sperm frozen catfish (Pangasius pangasius) products.
\end{abstract}

Keywords : Frozen Semen, Catfish, Cryoprotectant, Glycerol

\section{Pendahuluan}

Pemenuhan permintaan benih dalam jumlah besar dan berkelanjutan masih menjadi kendala utama dalam proses produksi ikan patin (Kementerian Kelautan dan Perikanan, 2010). Peningkatan produksi benih patin baik jumlah dan kualitasnya perlu dijaga mengingat pemijahan ikan patin yang sering digunakan hanya dengan mengandalkan bantuan hipofisa (Saparinto, 2010). Salah satu alternatif lain yang bisa dilakukan untuk menyediakan benih ikan patin sepanjang tahun yaitu melalui penyimpanan spermatozoa (Sulmartiwi dkk., 2011). Penyimpanan spermatozoa dapat dilakukan dengan proses kriopreservasi. Proses kriopreservasi membutuhkan bahan pengencer dan krioprotektan untuk mempertahankan fertilitas spermatozoa (Hardijanto dkk., 2010).
Bahan pengencer susu skim dan kuning telur dapat digunakan di ikan karena telah diteliti pada ikan mas (Setyono, 2009). Gliserol telah dilaporkan efektif untuk digunakan sebagai krioprotektan pada European Catfish dibandingkan dengan krioprotektan lain (Ogier, 1999 dalam Muchlisin et al., 2004). Susu skim mengandung zat nutrisi, lipoprotein dan lesitin untuk melindungi spermatozoa dari pengaruh kejut dingin (cold shock) (Widjaya, 2011). Kuning telur mengandung lipoprotein untuk mencegah terjadinya cold shock pada saat proses pembekuan (Vishwanath and Shannon, 2000). Gliserol sebagai krioprotektan intraseluler dapat mempertahankan motilitas spermatozoa ikan pada saat post thawing (Diwan et al., 2010) serta dapat mencegah pembentukan kristal es pada proses kriopreservasi sehingga dapat mengurangi 
kematian dari spermatozoa pada saat dibekukan (Susilowati dkk., 2010). Motilitas dan viabilitas sperma merupakan parameter yang penting untuk keberhasilan proses fertilisasi. Motilitas sperma menggambarkan kemampuan spermatozoa untuk membuahi sel telur, semakin tinggi nilai motilitas maka semakin tinggi pula persentase hidup (viabilitas) spermatozoa tersebut (Junior dkk., 2005). Penggunaan gliserol dalam pengencer susu skim dan kuning telur ini diharapkan mampu melindungi spermatozoa ikan patin dari kematian selama proses pembekuan sehingga spermatozoa dapat digunakan dalam proses fertilisasi buatan.

Berdasarkan latar belakang yang ada, maka timbul permasalahan yaitu bagaimana pengaruh perbedaan konsentrasi gliserol dalam campuran susu skim dengan kuning telur sebagai bahan pengencer terhadap motilitas dan viabilitas spermatozoa ikan patin pada saat prefreezing dan post-thawing.

Tujuan dilakukannya penelitian ini adalah untuk mengetahui konsentrasi gliserol yang tepat dalam bahan pengencer susu skim kuning telur yang digunakan untuk pembekuan sperma ikan patin.

Manfaat penelitian ini ialah memberikan informasi bagi mahasiswa maupun masyarakat lain tentang penggunaan konsentrasi gliserol yang optimal dengan bahan pengencer susu skim dan kuning telur untuk digunakan dalam pembekuan sperma ikan patin. Penelitian ini sebagai salah satu upaya dalam meningkatkan produksi benih ikan patin melalui teknik kriopreservasi yang dapat diterapkan pada para pembudidaya serta memberikan informasi bagi balai pembenihan ikan maupun balai inseminasi buatan yang ingin mengembangkan produksi benih ikan patin melalui teknik kriopreservasi sel spermatozoa.

\section{Materi dan Metode}

Penelitian ini dilaksanakan di Laboratorium Taman Pendidikan (Teaching Farm) Fakultas Kedokteran Hewan Universitas Airlangga. Penelitian ini dilaksanakan pada bulan April 2013.

Alat-alat yang digunakan yaitu bak plastik, aerator, kain lap halus, gelas ukur, tabung reaksi, spuit, alumunium foil, mikroskop, beaker glass, water bath (pemanas air), spatula, termometer, timbangan digital, kertas saring, ministraw, dan pendingin/kulkas. Bahan yang digunakan dalam penelitan ini adalah 2 ekor induk jantan ikan patin yang berukuran $\pm 2 \mathrm{~kg}$, berumur \pm 2 tahun serta matang gonad, nitrogen cair, bahan pengencer (aquades $50 \mathrm{ml}$, susu bubuk skim $5 \mathrm{~g}$, kuning telur sebanyak 5\% dari total pengencer, penicillin $0,17 \mathrm{~g}$, fruktosa $0,5 \mathrm{~g}$, streptomycin 0,08 g, glisero 4,03 ml).

Perlakuan yang diberikan berupa kelompok konsentrasi gliserol yang berbeda dalam bahan pengencer susu skim kuning telur. Perlakuan A (konsentrasi gliserol 11\% dalam bahan pengencer susu skim kuning telur), Perlakuan B (konsentrasi gliserol 13\% dalam bahan pengencer susu skim kuning telur), Perlakuan C (konsentrasi gliserol 15\% dalam bahan pengencer susu skim kuning telur), Perlakuan D (konsentrasi gliserol 17\% dalam bahan pengencer susu skim kuning telur).

\section{Persiapan Penelitian}

Sterilisasi alat-alat yang digunakan selama penelitian dengan cara dicuci dengan air bersih kemudian dikeringkan dan dimasukkan ke lemari pemanas dengan suhu $\pm 40^{\circ} \mathrm{C}$ selama 60 menit serta mempersiapkan bahan-bahan sesuai dengan kebutuhan.

Pengambilan Sperma Ikan

Pengambilan sperma ikan patin dilakukan dengan cara stripping. Proses stripping dilakukan dengan cara mengurut secara perlahan pada daerah perut persis di depan papila alat kelamin sampai keluar cairan semen ikan yang berwarna putih dan kemudian ditampung dalam wadah (Slembrouck et al., 2005).

Pemeriksaan Makroskopis dan Mikroskopis

Pemeriksaan makroskopis meliputi volume sperma, konsentrasi sperma, bau sperma, warna sperma dan derajat keasaman $(\mathrm{pH})$ sperma. Pemeriksaan mikroskopis meliputi gerakan massa, gerakan individu, dan viabilitas menggunakan mikroskop dengan pembesaran 100x (Susilowati dkk., 2010).

\section{Pembuatan Bahan Pengencer}

Pengencer yang digunakan dalam penelitian ini adalah susu skim dan kuning telur yang ditambahkan dengan 4 macam konsentrasi gliserol yang berbeda. Konsentrasi gliserol yang digunakan dalam penelitian ini yaitu 11\%, 13\%, $15 \%$, dan $17 \%$. Komposisi bahan pengencer yang digunakan yaitu aquades $50 \mathrm{ml}$, susu bubuk skim $5 \mathrm{~g}$, kuning telur sebanyak 5\% dari total pengencer, penicillin $0,17 \mathrm{~g}$, fruktosa 0,5 $\mathrm{g}$, streptomycin $0,08 \mathrm{~g}$.

\section{Pembuatan Sperma Beku}

Sperma dicampur dengan larutan A hingga $50 \%$ dari volume akhir, kemudian larutan B 50\% dari volume akhir dan 
dimasukkan ke dalam lemari es secara bersama dengan suhu $3-5^{\circ} \mathrm{C}$ selama 1-1,5 jam. Setelah mencapai suhu $3-5^{\circ} \mathrm{C}$, larutan A dan larutan $\mathrm{B}$ dicampur secara bertahap dan perlahan melalui dinding tabung (gliserolisasi) selama 1 jam. Spermatozoa dibiarkan dalam suhu $5^{\circ} \mathrm{C}$ selama 2-6 jam agar bisa menyeimbangkan cairan intraseluler dengan diluter yang mengandung gliserol sebelum proses pembekuan dimulai (equilibrasi). Motilitas dan persentase hidup spermatozoa setelah equilibrasi diperiksa menggunakan mikroskop dengan perbesaran 400x, bila motilitas masih 60-70\% maka dilakukan filling sealing straw. Setelah itu dilakukan proses pre-freezing dengan cara meletakkan 1-2 cm di atas permukaan $\mathrm{N}_{2}$ cair selama 9 menit, diteruskan dengan proses freezing dengan menenggelamkan ministraw ke dalam $\mathrm{N}_{2}$ cair. Pemeriksaan motilitas setelah thawing dilakukan setelah proses freezing dengan menggunakan mikroskop perbesaran 400x. (Susilowati dkk., 2010)

\section{Pemeriksaan Motilitas Sperma}

Pemeriksaan motilitas massa dan individu dilakukan dengan perbesaran 100x dan 400x. Penentuan nilai motilitas massa berdasarkan besarnya gelombang pergerakan sperma sedangkan motilitas individu dengan cara perhitungan sperma yang bergerak cepat dan progresif (Susilowati dkk., 2010). Rumus perhitungan motilitas individu adalah sebagai berikut :

$\frac{\text { Jumlah Spermatozoa yang Motil Progresif }}{\text { Jumlah Spermatozoa yang Diamati }} \times 100 \%$

\section{Pemeriksaan Viabilitas Sperma}

Viabilitas sperma diamati dengan teknik sediaan ulas menggunakan zat warna eosin dan negrosin. Satu tetes kecil sperma dan satu tetes besar larutan eosin negrosin diletakkan pada object glass, kemudian zat warna dan sperma dicampur hingga homogen. Membuat preparat ulas tipis dan dikeringkan di atas nyala api, proses tersebut harus selesai dalam 15 detik. Pengamatan di bawah mikroskop dengan perbesaran 400x (Susilowati dkk., 2010).

\begin{tabular}{|l|}
\hline Jumlah Spermatozoa yang Hidup \\
Jumlah Spermatozoa yang Diamati
\end{tabular}

Analisis Data

Rancangan penelitian ini menggunakan RAL (Rancangan Acak Lengkap) dan analisis data dihitung dengan menggunakan uji ANOVA, dengan menggunakan 4 perlakuan dan 5 kali ulangan, kemudian dilanjutkan dengan Uji Jarak Berganda Duncan dengan selang kepercayaan $95 \%$.

\section{Hasil dan Pembahasan}

Hasil pemeriksaan semen segar secara makroskopis dan mikroskopis pada penelitian ini dapat dilihat pada Tabel 1 .

Hasil pemeriksaan motilitas dan viabilitas spermatozoa ikan patin dapat dilihat pada Tabel 2.

Motilitas spermatozoa ditentukan dari banyaknya jumlah spermatozoa yang bergerak dari suatu lapang pandang (Susilowati dkk., 2010). Pemeriksaan motilitas spermatozoa ikan patin dilakukan sebanyak tiga kali, yaitu saat sebelum diberi perlakuan (semen segar), sebelum dibekukan (pre freezing), dan setelah dibekukan (post thawing) .

Tabel 1. Data semen segar ikan patin

\begin{tabular}{|c|c|c|}
\hline \multicolumn{3}{|c|}{ Makroskopis } \\
\hline Parameter & Hasil Penelitian & Referensi \\
\hline Volume & $1,4 \mathrm{ml}$ & 1, $23 \mathrm{ml} \mathrm{(Japet,} \mathrm{2011)}$ \\
\hline Warna & Putih Susu & Krem-Putih Susu (Japet, 2011) \\
\hline Bau & Amis & Bau Khas Sperma / Amis (Mar'ati, 2007) \\
\hline $\mathrm{pH}$ & 7,5 & 7,14-7,85 (Fujaya, 2002) \\
\hline Konsistensi & Kental / Pekat & Sedang-Pekat (Japet, 2011) \\
\hline \multicolumn{3}{|c|}{ Mikroskopis } \\
\hline Konsentrasi (sel / ml) & $9,58 \times 10^{9}$ & $5,53 \times 10^{9}$ (Japet, 2011) \\
\hline Motilitas : & & \\
\hline Progresifitas & $76 \%$ & 70\%-99\% (Chew et al., 2010) \\
\hline Kecepatan & 3 & 3 (Japet, 2011) \\
\hline Gerakan Massa & +++ & $+++($ Japet, 2011) \\
\hline Viabilitas & $84 \%$ & $>70 \%$ (Fujaya, 2002) \\
\hline
\end{tabular}

Keterangan : $+++=$ membentuk gelombang besar dan banyak; $3=$ cepat 
Tabel 2. Hasil pengamatan motilitas dan viabilitas spermatozoa ikan patin

\begin{tabular}{|l|c|c|c|c|}
\hline Parameter Perlakuan & Gliserol 11\% & Gliserol 13\% & Gliserol 15\% & $\begin{array}{c}\text { Gliserol } \\
17 \%\end{array}$ \\
\hline Motilitas Pre Freezing (\%) & 60 & 65 & 60 & 60 \\
\hline $\begin{array}{l}\text { Selisih Motilitas } \\
\text { Pre Freezing dan } \\
\text { Post Thawing (\%) }\end{array}$ & 11 & 14 & 12 & 14 \\
\hline Motilitas Post Thawing (\%) & $49 \pm 5,48^{\mathrm{a}}$ & $51 \pm 10,25^{\mathrm{a}}$ & $48 \pm 9,75^{\mathrm{a}}$ & $46 \pm 4,18^{\mathrm{a}}$ \\
\hline Viabilitas Post Thawing (\%) & $58,2 \pm 10,35^{\mathrm{a}}$ & $59,2 \pm 14,27^{\mathrm{a}}$ & $57,8 \pm 10,89^{\mathrm{a}}$ & $53,6 \pm 7,44^{\mathrm{a}}$ \\
\hline
\end{tabular}

Keterangan : Huruf superskrip yang sama pada tiap baris menunjukkan tidak adanya perbedaan yang nyata $(\mathrm{P}>0,05)$.

Pemeriksaan motilitas pada sperma segar menunjukkan bahwa $76 \%$ sel spermatozoa masih bergerak, sehingga dapat digunakan pada proses penyimpanan. Hasil pemeriksaan motilitas spermatozoa pada saat pre freezing menunjukkan bahwa penggunaan konsentrasi gliserol $13 \%$ memiliki nilai motilitas tertinggi yaitu sebesar $65 \%$ dibandingkan ketiga perlakuan lain yang menunjukkan nilai motilitas sebesar $60 \%$. Hasil pemeriksaan motilitas spermatozoa saat post thawing menunjukkan bahwa penggunaan konsentrasi gliserol 13\% memiliki nilai rata-rata motilitas tertinggi yaitu sebesar 51 10,25 , sedangkan penggunaan konsentrasi gliserol 17\% menunjukkan nilai rata-rata motilitas terendah yaitu sebesar $46 \pm 4,18$.

Viabilitas spermatozoa dihitung dari jumlah spermatozoa hidup dan mati dalam suatu lapang pandang dengan jumlah total spermatozoa yang dihitung sebanyak 100 sel spermatozoa (Susilowati dkk., 2010). Proses pemeriksaan viabilitas dilakukan dua kali pada saat segar dan pada saat setelah dibekukan (post thawing). Pemeriksaan viabilitas pada sperma segar menunjukkan bahwa $84 \%$ sel spermatozoa masih hidup, sehingga dapat digunakan pada proses penyimpanan. Spermatozoa hidup dapat dilihat melalui bentuk dan warna spermatozoa yang berbeda. Hasil pemeriksaan viabilitas spermatozoa saat post thawing menunjukkan bahwa penggunaan konsentrasi gliserol 13\% memiliki nilai rata-rata viabilitas tertinggi yaitu sebesar 59,2 $\pm 14,27$, sedangkan penggunaan konsentrasi gliserol $17 \%$ menunjukkan nilai rata-rata viabilitas terendah yaitu sebesar $53,6 \pm 7,44$.

Berdasarkan hasil penelitian, persentase motilitas sebelum pembekuan (pre freezing) pada keempat perlakuan tersebut dapat dikatakan stabil karena menunjukkan selisih yang hampir sama yaitu antara 11\%-14\%. Penurunan motilitas tersebut diakibatkan efek dari cold shock. Salah satu efek negatif dari cold shock adalah menurunkan proses metabolisme spermatozoa (Gazali dan Tambing, 2002). Berdasarkan analisis statistik, rata-rata motilitas sperma ikan patin pada saat post thawing tidak memiliki perbedaan yang nyata $(\mathrm{P}>0,05)$. Beberapa faktor yang diduga menyebabkan terjadinya perbedaan yang tidak nyata pada nilai motilitas sperma ikan patin pada saat post thawing adalah spermatozoa yang belum matang dan rasio pengenceran yang kurang tepat.

Pelaksanaan penelitian ini pada bulan April sehingga kematangan gonad diduga menurun dan spermatozoa yang dihasilkan cenderung masih belum matang. Menurut Zairin (2000) dalam Sutrisna (2002), perkembangan dan aktivitas gonad ikan patin menurun pada bulan Maret sampai Juni dan optimal selama bulan November sampai Januari. Fujaya (2002) menambahkan bahwa stimulasi dan lama pergerakan spermatozoa dipengaruhi oleh kematangan spermatozoa. Suhu thawing yang digunakan dalam penelitian ini adalah sebesar $26^{\circ} \mathrm{C}$ dengan periode thawing selama 15 detik. Yavas and Bozkurt (2011), menyatakan bahwa suhu dan periode terbaik yang berpengaruh pada motilitas pada saat thawing adalah dengan suhu $35^{\circ} \mathrm{C}$ selama 30 detik. Steyn et al. (1985) dalam Francis et al. (2013) menambahkan bahwa proses thawing harus dilakukan dengan waktu yang singkat untuk menghindari kerusakan sel yang disebabkan oleh rekristalisasi. Mitokondria yang rusak akan menyebabkan putusnya rantai oksidasi. Akibatnya, pergerakan spermatozoa terhenti karena tidak ada lagi pasokan energi dari organel mitokondria yang berfungsi merangsang fungsi mikrotubula (Gazali dan Tambing, 2002). Rasio antara semen dengan bahan pegencer yang digunakan dalam penelitian ini adalah 1:50. Berbagai rasio pengenceran yang telah digunakan pada ikan antara lain 1:6 (Uddowla et al., 2011) hingga 1:60 (Adipu, 2011). Penentuan rasio pengenceran berdasarkan konsentrasi dari spermatozoa, konsentrasi sperma yang tinggi memerlukan rasio pengenceran yang tinggi 
begitu pula sebaliknya (Uddowla et al., 2011). Menurut Adipu (2011), motilitas sperma yang tinggi disebabkan karena bahan pengencer sudah memberikan ruang gerak yang baik bagi spermatozoa. Selain itu, semen yang encer mengandung kadar potassium sehingga pergerakan spermatozoa menjadi lebih aktif.

Penurunan motilitas yang terjadi pada konsentrasi gliserol $11 \%$, 15\%, dan $17 \%$ yang disebabkan oleh berkurangnya metabolisme sel spermatozoa ini terjadi akibat efek cold shock. Kejutan dingin (cold shock) dapat menyebabkan penurunan motilitas dan memicu terjadinya kerusakan langsung yang berpengaruh pada struktur dan fungsi seluler, salah satunya yaitu penurunan proses metabolisme spermatozoa (Gazali dan Tambing, 2002). Berdasarkan analisis statistik, rata-rata viabilitas spermatozoa ikan patin pada saat post thawing tidak menunjukkan adanya perbedaan yang nyata antara keempat perlakuan $(\mathrm{P}>0,05)$. Hal tersebut diduga akibat dari penggunaan waktu equilibrasi yang kurang tepat serta pengaruh suhu dan periode thawing yang kurang optimal.

Waktu equilibrasi yang digunakan dalam penelitian ini adalah selama 90 menit. Menurut Francis et al. (2013), salah satu faktor penentu dalam mempertahankan viabilitas spermatozoa adalah penggunaan waktu equilibrasi yang tepat. Equilibrasi yang terlalu lama akan menyebabkan gliserol akan menarik air secara berlebihan dan menyebabkan dehidrasi sel sehingga terjadi kerusakan sel spermatozoa (Best, 2006 dalam Arifiantini dkk., 2005). Apabila waktu equilibrasi kurang maka krioprotektan tidak mempunyai waktu untuk melakukan penetrasi ke dalam sel sperma sehingga tidak dapat melindungi sel sperma dengan baik (Francis et al, 2013). Proses thawing pada penelitian ini dilakukan dengan menggunakan suhu $26^{\circ} \mathrm{C}$ selama 15 detik. Menurut Yavas and Bozkurt (2011), proses thawing yang terbaik adalah dengan menggunakan suhu $35^{\circ} \mathrm{C}$ selama 30 detik pada spermatozoa grass carp. Proses thawing yang tepat dapat mencegah terjadinya pembentukan kembali kristal es (Lahnsteiner, 2000 dalam Yavas and Bozkurt, 2011). Pembentukan kristal es selama proses kriopreservasi sel spermatozoa menyebabkan terjadinya penumpukan elektrolit di dalam sel. Hal tersebut mengakibatkan terjadi kerusakan sel secara mekanik. Pembentukan kristal es dapat menyebabkan kerusakan organel seperti lisosom dan mitokondria sehingga dapat menyebabkan kematian pada spermatozoa (Gazali dan Tambing, 2002). Penurunan yang terjadi pada konsentrasi gliserol sebesar $11 \%$, $15 \%$, dan $17 \%$ dikarenakan oleh efek gliserol yang kurang baik dalam menggantikan air bebas dan mendesak keluar elektrolit-elektrolit pada saat proses pembekuan, sehingga elektrolit akan menumpuk dan merusak dinding sel sehingga pada waktu pencairan kembali (post thawing) permeabilitas membran plasma akan menurun dan sel akan mati (Gazali dan Tambing 2002).

\section{Kesimpulan}

Hasil penelitian dapat disimpulkan bahwa penggunaan konsentrasi gliserol $11 \%$ $17 \%$ pada pengencer susu skim dan kuning telur tidak memberikan perbedaan yang nyata terhadap persentase motilitas dan viabilitas spermatozoa ikan patin pada saat post thawing dalam teknik kriopreservasi sperma.

Perlu dilakukan pengujian lebih lanjut tentang pengaruh dari kematangan spermatozoa, suhu dan periode saat thawing, rasio pengenceran, dan waktu equilibrasi pada proses peyimpanan sperma beku ikan.

\section{Daftar Pustaka}

Adipu, Y., H. Sinjal, dan J. Watung. 2011. Ratio Pengenceran Sperma Terhadap Motilitas Spermatozoa, Fertilitas dan Daya Tetas Ikan Lele (Clarias sp.). Jurnal Perikanan dan Kelautan Tropis, 8 (1) : 48-55.

Arifiantini, R. I., I. Supriatna, dan Samsurizal. 2007. Penentuan Waktu Equilibrasi pada Pembekuan Semen Kuda Menggunakan Bahan Pengencer Susu Skim. Animal Reproduction, 9 (3) : 145-152.

Chew, P.C., Z.A. Rashid and R. Hassan. 2010. Application of Innovative Biotechnologies Regarding Aquaculture and Fisheries Sector in Malaysia: Cryopreservation Programme. Freshwater Fisheries Research Center. Malaysia. www.fao.org. 3 Juni 2013. 17 hal.

Diwan, A.D., S. Ayyapan, K.K. Lal, and W.S. Lakra. 2010. Cryopreservation of Fish Gametes and Embryos. Indian Journal of Animal Sciences, 80 (4) : 109-124.

Francis, T. C.A Devi, and M. Selvamagheswaran. 2013. Cryopreservaation of Carp Spermatozoa. Indian Journal of Science and Technology, 6 (5) : 4524-4530

Fujaya, Y. 2002. Fisiologi ikan : Dasar Pengembangan Teknologi Perikanan. PT Rineka Cipta. Jakarta

Gazali, M dan S. N. Tambing. 2002. Kriopreservasi Sel Spermatozoa. Hayati, 9 (1) : 27-32.

Hardijanto, S. Susilowati, T. Hernawati, T. Sardjito, dan T. W. Suprayogi. 2010, 
Buku Ajar Inseminasi Buatan. Universitas Airlangga. Surabaya. Hal 40.

Japet, N. 2011. Karakteristik Semen Ikan Ekonomis Budidaya : Mas (Cyprinus carpio), dan Patin (Pangasius hypothalamus). Skripsi. Institut Pertanian Bogor. Bogor. Hal : 20.

Junior, M.Z., S. Handayani dan I. Supriatna. 2005. Kualitas Sperma Ikan Batak (Tor soro) Hasil Kriopreservasi Semen Menggunakan Dimetilsulfoksida (DMSO) dan Gliserol 5, 10 dan 15\%. Jurnal Akuakultur Indonesia, 4 (2) : 145-151.

Kementerian Kelautan dan Perikanan. 2010. Laporan Akhir Kegiatan Penelitian : Teknologi Pembenihan Ikan Patin (Pangasius sp.) yang Dipelihara Secara Outdoor di Kolam yang Dipupuk. Badan Penelitian dan Pengembangan Kelautan dan Perikanan. Sukamandi.

Mar'ati, K. 2007. Pengaruh Dosis dan Lama Penyimpanan Pengencer Susu Skim Kuning Telur Terhadap Kualitas Semen Ikan Mas (Cyprinus carpio L.). Skripsi. Jurusan Biologi Fakultas Sains dan Teknologi. Universitas Islam Negeri Malang.

Muchlisin, Z.A., R. Hashim, and A.S.C. Chong. 2004. Preliminary Study on The Cryopreservation of Tropical Bagrid Catfish (Mystus nemurus) Spermatozoa; The Effect of Extender and Cryoprotectant on The Motility After Short-Term Storage. Theriogenology, 62 (2004) : 25-34.

Saparinto, C. 2010. Usaha Ikan Konsumsi di Lahan $100 \mathrm{~m}^{2}$. Penebar Swadaya. Jakarta.

Setyono, B. 2009. Pengaruh Perbedaan Konsentrasi Bahan pada Pengencer Sperma Ikan "Skim Kuning Telur" terhadap Laju Fertilisasi, Laju Penetasan dan Sintasan Ikan Mas (Cyprinus carpio L). GAMMA, V (1) : 01-12.

Slembrouck, J., O. Komarudin, Maskur. dan M. Legendre. 2005. Petunjuk Teknis Pembenihan Ikan Patin Indonesia, Pangasius djambal. Terjemahan: Subandi, A dan Khan, Z. IRD dan Pusat Riset Perikanan Budidaya, Badan Riset Kelautan dan Perikanan. Jakarta.
Sulmartiwi, L., E. Ainurrohmah, dan A. S. Mubarak. 2011. Pengaruh Konsentrasi Air Kelapa Muda dan Madu dalam $\mathrm{NaCl}$ Fisiologis Terhadap Motilitas dan Lama Hidup Spermatozoa Ikan Patin (Pangasius pangasius). Jurnal Ilmiah Perikanan dan Kelautan, 3 (1) : 67-71.

Susilowati, S. Hardijanto, T. W. Suprayogi, T. Sardjito, dan T. Hernawati. 2010. Penuntun Praktikum Inseminasi Buatan. Airlangga University Press. Surabaya.

Sutrisna. 2002. Keragaman Kualitas Sperma Ikan Patin (Pangasius hypopthalmus Sauvage) pada Bulan Oktober 2000Februari 2001. Skripsi. Jurusan Budidaya Perairan. Fakultas Perikanan dan Ilmu Kelautan. Institut Pertanian Bogor.

Uddowla, M.H., U. Salma, M.M. Rahman, M.S. Hossain and M.F.A. Mollah. 2011. Effect of Diluents, Dilution Ratios and Cryoprotectants for The Cryopresevation of Thai Sharpunti (Barbodes gonionotus) spermatozoa. International Journal of Natural Sciences, 1 (2) : 44-51.

Vishwanath, R. and P. Shannon. 2000. Storage of Bovine Semen in Liquid Frozen State. Animal Reproduction Science, $62: 23-53$.

Widjaya, N. 2011. Pengaruh Pemberian Susu Skim dengan Pengencer Tris Kuning Telur terhadap Daya Tahan Hidup Spermatozoa Sapi pada Suhu Penyimpanan $5^{\circ} \mathrm{C}$. Sains Peternakan, 9 (2) : 72-76.

Yavas, I., and Y. Bozkurt. 2011. Effect of Different Thawing Rates on Motility and Fertilizing Capacity of Cryopreserved Grass Carp (Ctenopharyngodon idella) Sperm. Biotechnol \& Biotechnol. 25 (1) : 2254-2257. 